\title{
Time spent by doctors on medical audit
}

\author{
Kenneth Davison, Retired Consultant Psychiatrist, Chairman, Trust Medical Audit \\ Committee; and LeSLey SMITH, Medical Audit Officer, Newcastle Mental Health \\ NHS Trust, St Nicholas Hospital, Newcastle upon Tyne NE3 3XT
}

\section{Background}

The Newcastle Mental Health NHS Trust Medical Audit Committee has become increasingly concerned with the problem of doctors within the Trust being unable to find sufficient time to devote to medical audit.

All doctors are now required to be involved in audit (DoH, 1991). The Committee decided to conduct a survey in order to establish whether the Department of Health's standard is being met, and also to gather information on levels of audit activity, and how doctors are finding time to be involved in audit.

Trust doctors are involved with meetings of the following audit groups: Trust Medical Audit Committee; St Nicholas Hospital; Hadrian Clinic, Newcastle General Hospital; Plummer Court (Drug and Alcohol Service); Claremont House (Psychotherapy); Royal Victoria Infirmary Liaison Psychiatrists; Regional Old Age Psychiatry Audit Group; Regional Child and Adolescent Psychiatry Audit Group; Regional Group for Medical Audit in Psychiatry; Royal College of Psychiatrists Working Party on Audit in Child Psychiatry.

\section{The study}

A short questionnaire was devised and, with the approval of the Newcastle Division of Psychiatry, distributed to all senior house officers (SHOs), registrars (Rs), senior registrars (SRs) and consultants known to be working in June 1992 in units managed by the Trust. The anonymous replies were sent to the medical audit officer, who collated the results three weeks after sending out the forms. No reminders were sent.

The Medical Audit Committee discussed the results, and its conclusions are incorporated into this report.

\section{Findings}

Response rate

Replies were received from 34 out of 54 doctors; a response rate of $63 \%$. One reply came from a nonTrust unit, and this was excluded from the study, leaving 33 responses for analysis. The response was slightly higher from SRs and consultants $(68 \%$ response) than from SHOs and Rs (50\% response). Two out of the nine Trust Medical Audit Committee members did not reply. Replies were received from all eight workbases.

\section{Attendance at audit meetings}

Three doctors (one $\mathbf{R}$ and two SRs) did not know of any audit meetings for their workbase or specialty. For two of these doctors, workbase meetings are, in fact, held on a monthly basis.

In all, four trainees and one consultant $(15 \%$ of respondents) said that they had never attended an audit meeting for their current workbase or specialty. However, in reply to a question regarding the amount of time spent at audit meetings at any location in the six months prior to the questionnaire, every respondent gave a figure. The amounts ranged from one to $\mathbf{4 0}$ hours. Replies were sometimes estimates, but the approximate average is nine hours per six months ( 1.5 hours per month). Consultants tended to spend more time at meetings than trainees, reflecting their involvement in the Trust Medical Audit Committee and regional groups.

Two-thirds of trainee doctors did not have to "find" time in order to attend audit meetings, and said that it was timetabled (i.e. time dedicated for audit meetings) and "part of the job". A minority of trainees (in particular the SRs) mentioned that attendance at meetings was at the expense of other activity, or that time had been found by "working efficiently in other duties".

Conversely, the vast majority of consultants described how audit meetings were attended at the expense of other activities. Five consultants specifically mentioned that clinical work was affected in some way. Some commented that work missed due to attendance at meetings had to be caught up later, in personal time. Several mentioned that it was very difficult to find the time to attend meetings.

A few comments on the structure of audit meetings were made. These suggested that meetings were sometimes poorly attended, but were valuable. One trainee doctor mentioned that meetings "need a good chairman to direct proceedings and make clear decisions." 


\section{Training for audit}

Half of the consultants who replied had attended a training event for audit (seminar, conference etc.), but three-quarters of the trainees had not. A total of 12 doctors had attended events, which lasted from two hours to three days. Several mentioned that they had used study leave for the purpose.

\section{Involvement in audit projects}

Of respondents, $73 \%$ had been involved in an audit project at some time (whether while working within the Trust or not). The maximum number of projects that a doctor had worked with was four, with a median of one. Of those who had been involved, over half had been connected with more than one project. This was most noticeable with the consultants - out of 12 who had worked on a project, ten had been involved with two or more projects.

Four of the five doctors who had not attended audit meetings for their workbase or specialty, had been involved with projects.

The time spent involved with audit projects varied widely, from 15 minutes to 50 days! An accurate average cannot be calculated due to some respondents being unable to estimate the time spent. However, it appears that involvement in a project normally requires time equivalent to several full working days. When asked how time was found in order to carry out projects, doctors gave the following replies: all own time (4); mostly own time (7); half own time, half working day (8); mostly working day (4); and all working day (nil).

Hence, none of the doctors who replied were able to carry out audit work completely within their working day. The four doctors who were able to mostly use their working day were all SRs who said that they used research time. Consultants also used research time, but, as with audit meetings, personal time and other activities, including clinical sessions, suffered so that audit could be carried out.

\section{How worthwhile is time spent on audit?}

Thirty doctors answered this question - seven found the time spent very worthwhile, and 20 moderately worthwhile, leaving only three (all trainees) who had found the time unworthwhile in some respect.

\section{Conclusions and next steps}

A majority of doctors working within the Newcastle Mental Health NHS Trust in June 1992 have participated in audit activities in some way and, despite some having to use personal time and reduce time spent with patients, have found audit worthwhile.

Consultants, in particular, found it difficult to find time to be involved with audit projects. Nevertheless, nearly three-quarters of the respondents have been involved in projects, and, given the increasing demands on consultants' time and the short period that trainees stay with the Trust, this is a creditable finding.

An important finding was that no doctor who had been involved with an audit project had been able to carry out the work completely within his or her working day. Not having time set aside for audit may well have prevented other doctors from participating. To quote the Health Circular Medical Audit in Hospital and Community Health: "it is the responsibility of local managers to ensure that adequate resources are available to support the agreed audit programme ... The practice of medical audit requires time from both consultants and trainee doctors. Additional time will be required for those co-ordinating activities. This should be reflected in locally agreed job plans."

The survey also highlighted the lack of training in audit, particularly among trainees. This matter is now being addressed by the Northern Regional Group for Medical Audit in Psychiatry. A consultant update session on audit is planned, and a training day on medical audit for trainees in psychiatry has been held.

The Medical Audit Committee agreed that the need to provide time for doctors to carry out medical audit should be drawn to the attention of the Division of Psychiatry and the Trust management. Medical audit is a significant initiative which has the important aims of improving the quality of patient care and enhancing medical education. This survey has demonstrated that doctors are fully committed to the initiative, and continued commitment will serve to further benefit both patients and themselves. Unless time is specifically allocated, doctors may not be able to sustain their enthusiasm for medical audit, but which other activity can be sacrificed?

\section{Acknowledgements}

The co-operation of Newcastle Mental Health NHS Trust psychiatrists in the survey is gratefully acknowledged.

\section{Reference}

Department of Health (1991) Health Circular 91(2) Medical Audit in Hospitals and Community Health. 